\title{
Mesilane slaavi kultuuri sümbolkeeles
}

\author{
Aleksandr Gura
}

Vladimir Propp selgitas omal ajal muinasjutusüžeede ja kalendripühade näitel keeruliste teksti- ja tavandivormide jaotatavust üksikelementideks, selliste elementide kogumi lõplikkust, nende korduvust, taastoodetavust ja stereotüüpsust. V. Proppi morfoloogia idee osutus viljakaks lähenemisel traditsioonilisele kultuurile tervikuna. Kultuuristereotüüpe õnnestus välja selgitada teiste, vaimse rahvakultuuri keerulisemalt organiseeritud fragmentide, sh rahvazooloogia (s.t keeles, rahvaluules, uskumustes, kommetes, rahvakunstis jmt kajastatud traditsiooniliste loomakujutluste) analüüsi käigus.

Paikkondlike slaavi traditsioonide materjali kõrvutav analüüs lubas tuua välja loomade kui eriliste mütoloogiliste tegelaskujude relevantsete tunnuste invariantse kogumi ja luua loomariigikujutluste üsna täieliku kirjelduse mudeli.

Loomale iseloomulikud tunnused avalduvad erinevatel tasanditel. Keelelisel tasandil kuuluvad siia loomade tavalised ja tabunimed, pärisnimed ja epiteedid, morfoloogilisel tasandil välimuse (terve keha või selle osa) eriomadused ja muutused, samuti atribuudid; "sotsiaalsel" tasandil looma hierarhiline staatus, tema sugu, tõug, kvantitatiivsed karakteristikud, sidemed ja suhted teiste olendite ja objektidega, aga ka geneesi omapärad; tegevustasandil looma iseloomulikud toimingud, teatud objektile suunatud tegevused ja nende funktsionaalne suunatus, koostöö teiste loomadega, looma roll reprodutseerimis-, rakendus- ja kommunikatsiooniobjektina. Looma tegevust iseloomustavate tunnustega on tihedalt seotud tema akustilised ja kõnelised väljendused, mõned füüsilised ja psüühilised omadused, aga ka olekuviisid (liikumine, ilmumine, kadumine), lokatiivsed ja temporaalsed karakteristikud. Selline tunnuste koguhulk annab võimaluse igakülgselt üles ehitada maailmapildi terviklik fragment, välja selgitada kultuurikeele zooloogiline kood, selle sügavam mõte ja sisemine struktuur. Metodoloogiliselt on antud lähenemine rakendatav ka teistele kujutlussfääridele: näiteks deemonlike olendite, loodusstiihiate, taimede, toidu, majakraami jne kirjeldusele.

http://haldjas.folklore.ee/tagused/nr24/gura.pdf 


\section{Aleksandr Gura}

Rahvakultuuris vastab igale loomariigi tegelasele iseloomulike tunnuste teatud invariantne tervikkogum, mis korreleerub antud kuju konkreetse tunnustekogumiga igas paikkondlikus traditsioonis. Igas sellises eraldi traditsioonis valib kultuurikeel välja looma teatavad omadused, atribuudid, predikaadid jmt, varustades need sümbolilise tähendusega, ja jätab teised karakteristikud kultuuri raamidest välja, ei kaasa neid kultuurikonteksti. Seejuures võib üks ja sama loom tekitada erinevaid, sageli seostamata sümbolilisi tähendusi. Üritame rahvazooloogia ühe tegelase, mesilase näitel selgitada sümboli tekke mõningaid, kultuurikeelele omaseid mehhanisme.

Loomade rahvalik klassifikatsioon ühendab putukad muude ilgete roomajatega, liites need rea ühistunnuste ja -nimetuste alusel kurjusega seotud ktooniliste loomade, üldjuhul kurja allilma olevuste ühisklassi. Ilgete roomajate hulka kuuluvad eelkõige maod, konnad jt kahepaiksed, aga ka putukad, hiired, usjad kalad, ussid ja tõugud. Mesilaste ja roomajate sugulust tõendab näiteks poola uskumus müütilisest lohemaost roinicast, kes mesilas elades laseb suust välja mesilassülemeid, mistõttu mesilased paljunevad hästi. ${ }^{1}$

Putukate, sh ka mesilaste sümboolikas mängib olulist rolli hulgalisuse tunnus. See tunnus ühendab mesilasi sümbolina tähtede, lume, vihmapiiskade, pisarate, tulesädemete, liiva ja muu selletaolisega. Nii ennustab jõuluöö täherohkus taevas suveks palju mesilasi; mõistatustes esinevad tähed mesilastena ja mesipuu ümber keerlevad mesilased sarnastuvad lumetuisuga; unenägu peret heitvatest mesilastest tõlgendatakse lume, vihma või pisarate endena; kolmekuningapäeva ennustustes sümboliseerivad sädemed mesilasi (kuhupoole lendavad sädemed, sealt tulevad kevadel mesilased); esimese kevadise kõue ajal puistatakse tarude ette liiva, et tarud oleksid mesilasi täis jne. Mesilaste seos vihmaga ühendab neid ka roomajate ja kahepaiksete ning muude ktooniliste olevustega, eriti aga surnutega, kellel on slaavlaste rahvauskumuste kohaselt võim ilma üle ja kes võivad saata vihma või põuda.

Mesilase ktoonilised omadused avalduvad valgevene loitsus nende müütilise kalju sisemusest pärinemise motiivis: mesinikud paluvad sünnitada "neiukese-mesilase" ja saata endale mesilasi, pöördudes morskaja-gorskaja tsaritsa (vete ja mägede valitsejanna) poole, kes elab kaljukoopas, millest ööl ja päeval tulevad lennates mesilased (Mogiljovi kubermang - Romanov 1891: 157). Slaavlastele on hästi tuntud ka uskumused mesilase kujul ilmuvast hingest. 


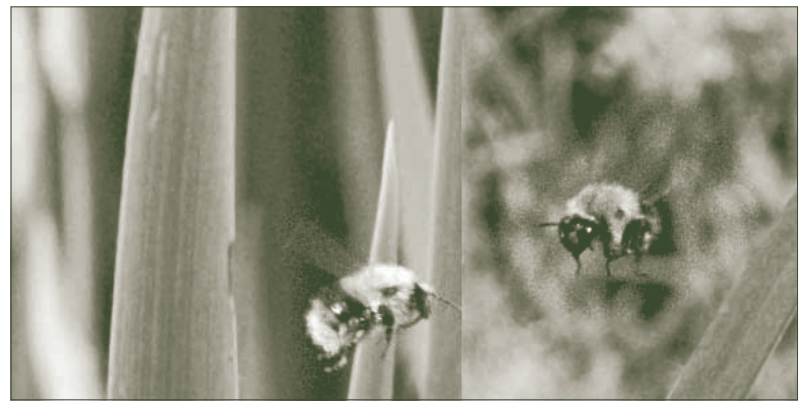

Foto 1. Metsmesilased. Andres Kuperjanovi foto 2002.

Näiteks Bulgaarias kuulatasid palvetajad hingedepäeval mesilaste ja kärbeste suminat, arvates, et need on nende lahkunud lähedaste hinged (Georgijeva 1983: 127). Idaslaavlaste unenäoseletustes esinevad mesilased sageli surmaennustajatena.

Samas paistab mesilane teiste putukate hulgast silma oma jumaliku, taevaliku loomu poolest. Selles suhtes on talle putukatest lähedased vaid lepatriinu ja siidiuss. Seletusmuistendites vastandatakse jumala loodud mesilasi kimalastele, vapsikutele, herilastele või kärbestele, kelle lõi jumalaga võistelnud saatan. Bulgaaria legendides esineb mesilane vahendajana jumala ja saatana vahel. Mesilase taevalikku loomust ja tema kahe maailma - maise ja taevaliku - vahelise vahendaja rolli tõendab motiiv poola muinasjutus Leidlik sulane: sulane kisub mesilas vargil käinud hundi suust mesilase nõela välja ja teeb sellest redeli, mida mööda ronib taevasse (Katowice vojevoodkond - Udziela 1903: 178-179).

Slaavlased austavad mesilast igal pool kui süütut jumalalooma. Poolakad nimetavad teda jumalaputukaks (boży robak) (Moszyński 1967: 550), Polesje ukrainlased jumala tarkuseks (божа мудростьVolõõnia oblasti Ljubešovski rajoon), venelased jumala pühakuks (божья угодница) (Dal 1957: 216). Bukoviina russiinid (ehk ruteenid, endanimetus rusnakid) ja serblased peavad mesilast pühaks (Bukowina 1899: 165; Djordjevic 1958: 216). Mesilase tapmine on suur patt, sest tema vahast tehakse küünlaid, mis põlevad kirikus jumalate palge ees (Dal 1957: 948; Kolberg 1963a: 150 (Lublini vojevoodkond); Djordjevic 1958: 216 (Serbia, Montenegro ja Hertsegoviina )). Idaslaavlased on veendunud, et mesilane nõelab vaid patust inimest (Dal 1957: 948; Afanasjev 1994: 385; Dmitrijev 1869: 


\section{Aleksandr Gura}

259 (Mogiljovi kubermang)) ja mesilaste kui jumaliku loomuga olenditega tarusse ei löö kunagi välk (Afanasjev 1994: 385 (Rovno (Rivne) oblastist autori üleskirjutus, Gomeli oblastist A. B. Strahhovi üleskirjutus)). Poolakad arvavad, et mesilastele ei hakka kunagi külge kuri nõidus (Szyfer 1975: 162 (Suwałki vojevoodkond)).

Rida üksikmotiive, mida leidub erinevates slaavi uskumustes mesilastest, rahvaluuletekstides ja mesilaste pidamise kombestikus, ühendavad mesilast sümboolselt Jumalaema kujuga. Rahvatraditsioon ei kingi mesilasele üksnes puhtust ja pühadust, vaid omistab talle ka neitsilikkuse ja abielutuse. Valgevene loitsudes nimetatakse teda neiukeseks (dzjavitsa-ptšalitsa) (Mogiljovi kubermang - Romanov 1891: 157, 158), vene lõikuslaulus sümboliseerib ta kaunist tütarlast (krasnaja devka) (Pihkvamaa - Zemtsovski 1975: 36 ), valgevene legendis muutuvad mesilasteks keset merd kivil istuva kauni neitsi pisarad (Minski kubermangu Borissovi maakond Šein 1893: 353). Vene mõistatustes kirjeldatakse mesilasi vallaliste neidude või nunnadena:

Istuvad neiud pimedas vangikojas ja koovad võrku ilma nõela ja niidita; istub nunnake ja koob võrgukest [---] (Samaara kubermang - Sadovnikov 1901: 149, 151).

Istuvad nunnakesed pimedas vangikojakeses [---] (Kaluuga kubermang - Sadovnikov 1901: 148).

Ukraina ja valgevene muinasjuttudes väldib mesilane kavaluse abil abielu kimalasega: lükkab pulmad sügisesse edasi, siis aga kõhnaks jäänud kimalane sureb (Barag \& Berezovski \& Kabašnikov \& Novikov 1979: $98\left(-282^{* *}\right)$ ).

Neitsi Maarja omaga sarnast süütu eostuse motiivi kohtab serbia mesilase-uskumustes. Arvatakse, et jumal ise on kehtestanud mesilaste paljunemise ilma paaritumiseta: emamesilane lihtsalt muneb ja sellest tulevad mesilased (Užice ringkond - Djordjevic 1958: 211). Sama motiiv peegeldub vene mesilase-mõistatustes:

Ei ole neiu, ei lesk ega abielunaine, aga lapsi sünnitab; Elab ei neiu, ei naine, ei sõdurinaine, ei lesk ega abielunaine; Meest tal ei ole, pattu ei tee, aga lapsi on palju (Samaara kubermang Sadovnikov 1901: 151). 
Mesilaste pidamisega seotud pühade hulgast paistab eriti välja Õiglase Anna (Jumalaema eostamise) päev (9/22. XII). Sel päeval palusid Kubani mesinikud palvetes mesilasperede eostust, mida võrreldi Neitsi Maarja sünnitanud Püha Anna eostumisega:

Anna eostas panna püha Jumalaema [---] samuti teiegi, mu mesilased, alustage tööd jumala nimel, tihedad parved, paksud meed (Toporov 1975: 22).

Mesinikud tähistasid samuti Ignatius Jumalakandja päeva (20. $\mathrm{XII} / 2 . \mathrm{I}$ ), mis on kristlikus traditsioonis seotud Jumalaema sünnitusvalude algusega: Lõuna-Bulgaarias tulistasid mehed sel päeval püssidest, et mesilased paremini paljuneksid, majades süüdati mesilaste heaoluks küünlad, mis põlesid terve päeva (Peštera rajoon - Rodopi 1994: 86).

Mesilaste paljunemise akti ja Jumalaema sünnitust ühendav kristlik sümboolika leiab samuti rituaalse kehastuse mesilaste pidamise praktikas. Et mesilasi oleks palju, võtavad Kielece vojevoodkonna poolakad jõulude ajal kirikusse kaasa niidiga keripulga, millega vöötavad missalt tagasi tulles tarud - sarnaselt sellega, kuidas vöötatakse õlgedega jõulude ajal viljapuid, et need vilja kannaksid (Kolberg 1963b: 211).

Jumalaema kuju otsest analoogiat kujutab endast mesilaste esiema serbia legendis. Ema nuttis taga oma ainukest hukutatud ja siis üles tõusnud poega. Jumal halastas ja andis talle tagasi elus ja vigastamata poja, kelle saatan oli veskipaisu uputanud, aga ema pisarad muutusid mesilasteks (Homolje-Djordjevic 1958: 209-210). Seoses kristliku ülestõusmismotiiviga on näitlik ka ukrainlaste komme mesilasi lihavõttepühadel õnnitleda - soovida õnne Kristuse ülestõusmise puhul: Kristus on üles tõusnud! (Kilimnik 1962: 307.)

Mesilase ja Jumalaema korrelatsioon ilmneb keelelisel tasandil - nende nimetustes: matka (emamesilane) ja Mater (püha ema). Keeles ja rahvaluuletekstides esinev emamesilase keiserlik sümboolika ühendab teda Jumalaema kui Taeva Keisrinnaga (tsaritsa). Tsaritsa on üks emamesilase vene nimetustest (Dal 1980: 571). Ukraina palves pöördutakse emamesilase poole sõnadega:Tere päevast, keisrinna-emamesilane! (Kilimnik 1962: 298) Vene muistendis muutis jumal emamesilaseks kunagi maa peal elanud raudhammaste ja sarvedega müütiliste inimeste valitsejanna, nii nagu tema 


\section{Aleksandr Gura}

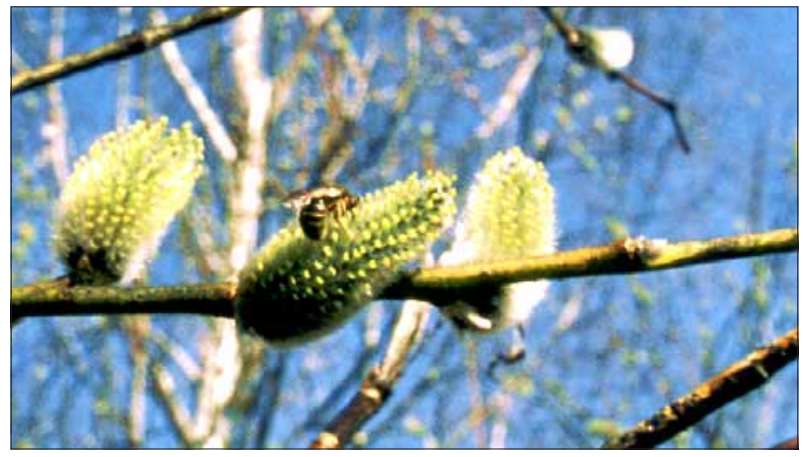

Foto 2. Kevadine mesilane. Andres Kuperjanovi foto 2001.

uskmatu ja sõjaka rahva mesilasteks (Vitebski kubermangu Sebežski maakond - Zelenin 1914: 134). Ukraina ja valgevene loitsudes nimetatakse emamesilast nagu Jumalaemagi Marijaks (Tšernigovi maakond - Pila 1898: 6) või Marjaskaks (Mogiljovi kubermang Romanov 1891: 158). Vene kevadelauludes esinevad mesilase ja Neitsi Maarja kuju sarnastes kontekstides: nad toovad välja võtmed, millega lukustatakse talv ja keeratakse suvi lukust lahti (Zemtsovski 1970: 283-284).

Lõpuks on mesilase Jumalaema-sümboolika avastamises oluline tähendus ka Jumalaema kultusel mesilaste pidamise tavandites. Lõuna-Bulgaarias omistatakse Jumalaemale mesindusega tegelemist ning peetakse teda mesilaste ja nende omanike kaitsjaks. Sellepärast pakutakse Jumalaema Uinumise pühal ehk rukkimaarjapäeval (15./28.VIII) kirikus mesilaste sigimise suurendamise eesmärgil õnnistatud mett (Popov 1993: 66). Haskovo ringkonnas kostitatakse rukkimaarjapäeval lähedasi ja naabreid meega Jumalaema auks, kes ise tegeles minevikus mesindusega ja kehtestas spetsiaalselt meemüümiseks jumalaema paastu (Rodopi 1994: 113, 111). Valgevenes palvetavad mesinikud mesilaste eest kolmapäeval, taevaminemispüha eelõhtul, asetades küünla Jumalaema ikoonile (Mogiljovi kubermang - Romanov 1891: 157-158), Poolas Masoovias minnakse jõulude või lihavõttepühade ajal kohe pärast kirikust tulekut tarude juurde ja pöördutakse mesilaste poole Neitsi Maarja palvega (Ostrołęka vojevoodkond - Kolberg 1970: 404).

Kultuurikeele märgi - antud juhul mesilase kui mütoloogilise tegelase - sümboliline sisu moodustub erinevatest semantilistest 
elementidest. Sellisteks on mesilase nimetused ja epiteedid rahvaluuletekstides, erinevad omadused (süütus, pühadus, naiselik alge), sealhulgas füüsilised (paljunemine süütu eostuse teel) ja "sotsiaalsed" (abielutus), kvantitatiivsed näitajad (hulgalisus), hierarhiline spetsialiseerumine ("keisrinna" - emamesilase - olemasolu), staatus teiste mütoloogiliste tegelaste suhtes (kaitsja olemasolu Neitsi Maarja või teiste pühakute kujul), genees (tekkimine pisaratest, põlvnemine sarvedega inimestest või loomine Jumala poolt), atribuudid (suve lukust lahti keeravad võtmed), kohad (koobas kalju sees), funktsioonid (nõelab patust inimest) jm tunnused, mida omistatakse mesilasele kultuuri kontekstis ja mis saab sümbolilise koormuse. Selle personaaži sümbolilise sisu selgitamine kujutab endast semantilist rekonstruktsiooni, mille materjaliks on traditsioonilise rahvakultuuri mitmesugused vormid ja žanrid: sõnavara, uskumused, rituaalsed toimingud, rahvaluulemotiivid ja -süžeed, mis semantilise rekonstruktsiooni käigus moodustavad mosaiigina korrastatud tervikpildi.

Mesilase näide demonstreerib näitlikult kultuurikeelele omaseid sümbolistumise mehhanisme. Selles võib üks ja sama sümboliline tähendus olla väljendatud erinevate koodidega. Nii väljendub mesilase Jumalaema-sümboolika Maarja nime kohaldamises emamesilase märkimiseks (s.o verbaalse koodi abil), neitsist sünnitamise motiivis, uskumustes ja mõistatustes mesilastest (mentaalse koodi abil), küünla rituaalses asetamises Jumalaema ikoonile mesinike palvetamise ajal (tegevus- ja objektikoodi kaudu) jne. Mesilase jumalik loomus ilmneb tema epiteetides, temaga seotud seletusmuistendites, uskumustes ja keeldudes. Aluseks mesilase emaliku sümboolika rekonstrueerimisele on serbia seletusmuistend ja emamesilase nimetused. Mesilase keiserlikku sümboolikat tõendavad emamesilase nimetused keeles ja rahvaluuletekstides, aga ka tema müütilisest keisrinnast pärinemise motiiv vene muistendis. Poja elustumise motiiv esineb seoses mesilasega serbia muistendis surmatud poja emast ja kombes õnnitleda mesilasi lihavõttepühadel.

Slaavi omaga sarnane sümboolika ilmneb mesilasel ka mõnedes teistes traditsioonides (vt ka Toporov 1975: 23, 34-35), sh LääneEuroopa traditsioonis, kus mesilased ja tarud sümboliseerivad Neitsi Maarjat kui igasuguse magusa allikat (Lurker 1989: 188). Jumalaema motiive leidub slaavi rahvatraditsioonis peale mesilase ka mõnede muude loomade, sealhulgas teiste putukate sümboolikas, 


\section{Aleksandr Gura}

kuigi vähemal määral. Situatsioon, kus erinevad reaalid saavad ühed ja samad kultuuritähendused, tekitab sümbolilise homonüümia ja isofunktsionaalsuse. Nii on bulgaarlastel, makedoonlastel, poolakatel ja kašuubidel levinud lepatriinu nimetused Neitsi Maarja, Maarja, Jumalaema, Jumalaema lehmake (Gura 1997: 499). Lõunaslaavlased peavad siidiussi Jumalaema ussiks: makedoonlaste legendi kohaselt tekkis siidiuss sellest, et Jumalaema sülitas ta suust välja (Gura 1997: 377). Serblaste kujutluste järgi tekkis tigugi Jumalaema sülitusest (Gura 1997: 397). Jumalaemaga sarnastub mõnedes ukraina lauludes pääsuke (Gura 1997: 618). Horvaadid arvavad, et karpkala peas on Jumalaema kujutis koos Jeesuslapsega (Gura 1997: 756).

Mesilase kristliku sümboolikaga varustamine on tingitud kõigepealt sellest, et selline sümboolika mahtus kergelt kujutuste üldraamidesse mesilasest kui heast olendist ja inimestele kasutoovast väsimatust töötajast. Nende kujutlustega kooskõlas ei tõrjunud ta rahvalikku sümboolikat, pigem toimis sellega koos, seda omamoodi ümber töötades ja täiendades. Võib oletada, et Jumalaema asendas mingisugust teist, paganlikku tegelast. Kuid selle vanema kultuurikihi väljaselgitamine on eraldi ülesanne, mille lahendamiseks ei piisa vaid materjali sisemisest semantilisest rekonstruktsioonist, vaid on vaja süvamütoloogilist rekonstruktsiooni, mis nõuab laiemate võrdlusandmete kaasamist.

Kristliku algme domineerimine paganliku üle kõnealuses uskumuste kompleksis on tingitud erilisest kohast, mis on mesilastepidamisel rahvakultuuri üldsüsteemis. Oma autonoomsuse ja esoteerilisuse, ainult meestele-professionaalidele juurdepääsu tagajärjel sai see kultuurisfäär mitte ainult igivanade traditsioonide ja uskumuste arhailise kihi hoiukohaks, vaid paistis silma ka avatuse poolest raamatukultuurile, mille vahendajateks olid mesinikud kui külarahva harituim kiht. Raamatukultuur soodustaski kristliku elemendi sissetungi sellesse rahvakultuuri valdkonda.

Tõlkinud Nikolai Kuznetsov

\section{Kommentaar}

${ }^{1}$ Archivum Muzeum Etnograficznegu w Krakowie, nr I/147, s II/116, 1 8-8a (Tarnów). 
Aleksandr Gura

\section{Kirjandus}

Afanasjev 1994 = Афанасьев, Александр. Поэтические воззрения славян на природу 1. Москва: Индрик.

Barag \& Berezovski \& Kabašnikov \& Novikov 1979 = Бараг, Лев \& Березовский, Иван \& Кабашников, Константин \& Новиков, Николай (koost). Сравнительный указатель сюжетов: Восточнославянская сказка. Ленинград: Наука.

Bukowina 1899 = Geschichte der Bukowina 3: Die Bukowina unter der Herrschaft des österreichischen Kaiserhauses (seit 1774). Czernowitz: Commissionsverlag des k. k. Universitätsbuchhandlung H. Pardini.

Dal 1957 = Даль, Владимир. Пословицы русского народа. Москва: Гослитиздат.

Dal 1980 = Даль, Владимир. Толковый словарь живого великорусского языка 4. Москва: Русский язык.

Djordjevic 1958 = Đorðevic, Tihomir R. = Ђорђевиђ, Тихомир Р. Природа у вероваћ у и предану нашега народа 2. Српски етнографски зборник 72. Београд: Научно Дело.

Dmitrijev 1869 = Дмитриев, Михаил. Собрание песен, сказок, обрядов и обычаев крестьян Северо-Западного края. Вильна: Печатня А. Г. Сыркина.

Georgijeva 1983 = Георгиева, Иваничка. Българска народна митология. София: Наука и Изкуство.

Gura 1997 = Гура, Александр. Символика животньх в славянской народной традиции. Москва: Индрик.

Kilimnik 1962 = Килимник, Степан. Український рік у народніх звичаях в історичному освітленні 3: Весняний цикл. Вінніпег: Ukrainian Research Institute of Volyn.

Kolberg, Oskar 1963a. Dzieła wszystkie 17: Lubelskie 2. Wrocław \& Poznań: Polskie Wydawnictwo Muzyczne.

Kolberg, Oskar 1963b. Dzieła wszystkie 19: Kieleckie 2. Wrocław \& Poznań: Polskie Wydawnictwo Muzyczne.

Kolberg, Oskar 1970. Dzieła wszystkie 42: Mazowsze 7. Wrocław \& Poznań: Polskie Wydawnictwo Muzyczne.

Lurker, Manfred 1989. Słownik obrazów i symboli biblijnych. Tłumaczył K. Romaniuk. Poznań: Pallotinum.

Moszyński, Kazimierz 1967. Kultura ludowa Słowian II: Kultura duchowa 1. Warszawa: Książka i Wiedza. 


\section{Aleksandr Gura}

Pila 1898 = Пасечная книга. Vene Rahvusraamatukogu Sankt-Peterburis, käsikirjade osakond, f 777 (Pavel Tihhanovi fond), n 3, s 221, 8 l.

Рopov 1993 = Попов, Рачко. Кратък празничен народен календар. София: Етнографски институт с музей при БАН.

Rodopi 1994 = Родопи: Традиционна народна духовна и социалнонормативна култура. София: Етнографски институт с музей при БАН. Romanov 1891 = Романов, Евдоким. Белорусский сборник 5. Витебск.

Sadovnikov 1901 = Садовников, Дмитрий (koost). Загадки русского народа: Сборник загадок, вопросов, притч и задач. Санкт-Петербург.

Szyfer, Anna 1975. Zwyczaje, obrzędy i wierzenia Mazurów i Warmiaków. Olsztyn: Pojezierze.

Šein 1893 = IIейн, Павел. Материалы для изучения быта и языка русского населения Северо-Западного края 2. Сборник ОРЯЗ 57. СанктПетербург.

Zelenin 1914 = Зеленин, Дмитрий. Описание рукописей Ученого архива Императорского Русского географического общества 1. Петроград: Императорское Русское Географическое Общество.

Zemtsovski 1970 = Земцовский, Изалий (koost). Поэзия крестьянских праздников. Ленинград: Советский писатель.

Zemtsovski 1975 = Земцовский, Изалий (koost). Русские народные песни, напетые Анной Андреевной Степановой. Ленинград: Советский композитор.

Toporov 1975 = Топоров, Владимир. К объяснению некоторых славянских слов мифологического характера в связи с возможными древними ближневосточными параллелями. Славянское и балканское языкознание: Проблемы интерференции и языковых контактов. Москва: Наука, lk 3-49.

Udziela, Seweryn 1903. Dwie bajki ze Sławkowa w Królestwie Polskiem. Lud 9. Wroclw \& Lwów: Tow. 